J.E. Raber-Durlacher

N.J. Weijl

M. Abu Saris

B. de Koning

A.H. Zwinderman

S. Osanto

\section{Oral mucositis in patients treated with chemotherapy for solid tumors: a retrospective analysis of 150 cases}

Published online: 24 February 2001 (C) Springer-Verlag 2001

The online version of the original article can be found at

http://dx.doi.org/10.1007/s005209900127

J.E. Raber-Durlacher $(\varangle)$ • N.J. Weijl

M. Abu Saris - B. de Koning - S. Osanto Department of Clinical Oncology,

Leiden University Medical Center,

Leiden, The Netherlands

E-mail: jraber@worldonline.nl

Phone: +31-71-5263464

Fax: +31-71-5266760

A.H. Zwinderman

Department of Medical Statistics,

Leiden University Medical Center,

Leiden, The Netherlands

J.E. Raber-Durlacher

Department of Periodontology,

Academic Center for Dentistry,

Louwesweg 1, 1066 EA Amsterdam,

The Netherlands

J.E. Raber-Durlacher

Department of Clinical Oncology, K-1-P, Leiden University Medical Center,

Albinusdreef 2, P.O. Box 9600,

2300 RC Leiden, The Netherlands

\section{Support Care Cancer (2000) 8:266-371}

Unfortunately, there were two errors in the original version of this article.

1. Patients and Methods section, page 367

"In total 1,089 cycles..." should be "In total 1,281 cycles..."

2. Legends of table 3, page 369

"Characteristics of the 1,281 chemotherapy cycles, i.e. 1,281 cycles without..." should be

"Characteristics of the 1,194 chemotherapy cycles, i.e. 1,194 cycles without..."

We very much regret this oversight. 